\title{
PENGUATAN EKONOMI BUMDES LUBUK KERTANG MELALUI PEMETAAN POTENSI DESA SECARA PARTISIPATIF
}

\section{STRENGTHENING THE ECONOMY OF LUBUK KERTANG BUMDES THROUGH PARTICIPATIVE MAPPING OF VILLAGE POTENTIALS}

\author{
Yeni Absah ${ }^{1 *}$, Endang Sulistya Rini ${ }^{2)}$, Farid Aulia ${ }^{3)}$
}

${ }^{1)}$ Fakultas Ekonomi dan Bisnis, Universitas Sumatera Utara. email: yeni.absah@usu.ac.id ${ }^{2}$ Fakultas Ekonomi dan Bisnis, Universitas Sumatera Utara. email: endang.sulistya @usu.ac.id

${ }^{3}$ Fakultas Hukum, Universitas Al-Azhar. email: faridaulia79@gmail.com

\begin{abstract}
ABSTRAK
Pengurus BUMDes harus memiliki kemampuan memahami potensi desa, menyusun tata kelola yang baik dimulai dari rencana sumberdaya yang dibutuhkan, jenis usaha yang dikembangkan, proses pelaksanaan secara partisipatif, transparan dan akuntabel. Kondisi eksisting BUMDes Lubuk Kertang masih perlu pembenahan dari pemahaman potensi desa, tata kelola, pemilihan dan pengembangan jenis usaha yang dikelola BUMDes secara berkelanjutan.Metode dalam kegiatan ini adalah melalui sosialisasi kegiatan pelatihan penguatan ekonomi BUMDes Lubuk Kertang Melalui Pemetaan potensi desa secara partisipatif, pelatihan penguatan ekonomi BUMDes Lubuk Kertang melalui pemetaan potensi desa secara partisipatif, penguatan tata Kelola melalui pengembangan unit usaha BUMDes Lubuk Kertang, serta monitoring dan evaluasi. Hasil dari program kemitraan kepada masyarakat ini adalah kelompok mitra dapat meningkatkan kemampuan dalam mengelola BUMDes dengan memilih dan mengembangkan jenis-jenis usaha yang ada berdasarkan potensi sumberdaya lokal desa melalui pemetaan potensi desa secara partisipatif dalam melakukan tata kelola BUMDes yang baik dan benar, sehingga mampu bersinergi dengan Pemerintah Desa Lubuk Kertang dan masyarakat sebagai pelaku wirausaha desa.
\end{abstract}

Kata Kunci: Peningkatan Kemampuan, Tata Kelola, Potensi Desa, Pemilihan dan Pengembangan Unit Usaha

\section{ABSTRACT}

Administrators must have the ability to understand the potential of the village, formulate good governance starting from the resource plan needed, the type of business developed, the implementation process in a participatory, transparent and accountable manner. The existing condition of BUMDes Lubuk Kertang still needs improvement from the understanding of village potential, governance, selection and development of types of businesses managed by BUMDes in a sustainable manner. The method in this activity is through the dissemination of training activities for economic strengthening of the Lubuk Kertang BUMDes through participatory mapping of village potentials, training on strengthening the economy of the Lubuk Kertang BUMDes through participatory mapping of village potential, strengthening governance through the development of the Lubuk Kertang BUMDes business unit, and monitoring and evaluation. The result of this partnership program with the community is that partner groups can improve their ability to manage BUMDes by selecting and developing existing types of businesses based on the potential of village local resources through participatory mapping of village potentials in carrying out good and correct BUMDes governance, so that they can work together. with the Lubuk Kertang Village Government and the community as village entrepreneurs.

Keywords: Capacity Building, Village Potential, Selection and Development Business Unit

\section{PENDAHULUAN}

Perhatian pemerintah terhadap dan di buktikan dengan di tahun 2015

muncul program dana desa. Agar dana desa pembangunan desa sudah ada sejak dahulu tersebut bermanfaat bagi kemajuan 
masyarakat dan bagi desa, maka perlu di bangun modal manusia desa yang akan merencanakan aktivitas produktif, mengorganisasikan dana dan sumber daya desa yang berpotensi [3]. Pemerintah juga telah menggerakkan BUMDes. Setiap desa harus memiliki kemampuan untuk mengelola dana tersebut untuk mengembangkan melalui kesatuan usaha yang berada pada satu payung BUMDes. Pengurus BUMDes juga harus memiliki kemampuan mengidentifikasi potensi sumberdaya lokal sebagai sumber pendapatan BUMDes, menyusun tata kelola yang baik dari rencana sumberdaya yang dibutuhkan, proses pelaksanaan sampai indikator tercapainya pengembangan BUMDes [5]. salah satu tujuan pendirian BUMDes adalah untuk membantu meningkatkan kesejahteraan desa, terutama dari kesejahteraan ekonomi.

Belum dimanfaatkannya BUMDes secara maksimal sebagai motor ekonomi desa tidak terlepas dari ketiadaan memahami dan mengidentifikasi potensi desa yang ada. Peta potensi desa menjadi instrumen yang sangat penting sebagai petunjuk untuk BUMDes membuat program kerja atau kegiatan. Dengan adanya peta potensi desa, Desa dapat membuat strategi prioritas pembangunan desa melalui pendayagunaan BUMDes [1]. Kondisi eksisting ditemukan pada BUMDes Lubuk Kertang yang masih dikelola secara konvensional. Unit usaha yang dikembangkan beberapa jenis usaha perdagangan dan jasa, mencakup: pertanian, perikanan, peternakan, home industry, dan usaha simpan pinjam belum mencerminkan ptensi Desa Lubuk Kertang yang sesungguhnya. Pengurus BUMDes Lubuk Kertang tidak mengetahui perihal tata kelola yang baik, khususnya identifikasi potensi sumberdaya lokal yang berkaitan dengan pemilihan dan pengembangan jenis usaha yang sesuai dengan sumbetrdaya lokal yang tersedia. Padahal kegiatan potensi desa merupakan bagian dari perencanaan dan strategi komprehensif untuk menciptakan BUMDes yang berkelanjutan. Kegiatan ini dilakukan untuk memastikan bahwa setiap potensi dapat digunakan untuk meningkatkan pembangunan desa, baik secara individu, organisasi warga dan lembaga lokal adalah faktor utama dalam penyusunan potensi desa dan tata kelola serta untuk penguatan BUMDes secara berkelanjutan.

Berangkat dari kondisi eksisting memunculkan sebuah gagasan baru untuk melakukan pelatihan penguatan ekonomi pengurus BUMDes Lubuk Kertang secara partisipasitif bersama masyarakat ke dalam setiap tahapan penguatan potensi desa, baik dalam hal pemetaan potensi desa, pemilihan unit usaha usaha, tata kelola, pengembangan unit usaha dan pengorganisasian, sehingga hasilnya pun dapat dinikmati secara bersamasama oleh semua masyarakat desa. Hasil pengabdian ini nantinya dapat mengembangkan potensi desa melalui penguatan BUMDES Lubuk Kertang, sehingga banyak manfaat yang dapat dirasakan oleh masyarakat, baik secara ekonomi maupun secara non-ekonomi. 
Berangkat dari pemahaman atas kondisi riil ini, maka pengabdi terpanggil untuk melakukan program mono tahun regular dengan judul "Penguatan Ekonomi BUMDes Lubuk Kertang Melalui Pemetaan Potensi Desa Secara Partisipatif”. Kegiatan ini diharapkan mampu direplikasi oleh pengurus BUMDes di desa lain dengan penyesuaian terhadap konteks lokal, sehingga mampu meningkatkan kapasitas dalam pengembagan BUMDes ke depannya.

Terdapat beberapa permasalahan mitra yang dapat dirumuskan antara lain:

1. Rendahnya kapasitas pengurus BUMDes Lubuk Kertang dalam memetakan potensi desa

2. Rendahnya/ minimnya kemampuan pengurus BUMDes Lubuk Kertang dalam pemilihan dan pengembangan unit usaha berdasarkan potensi desa yang ada

3. Rendahnya/ minimnya kemampuan pengurus BUMDes Lubuk Kertang melakukan sinergitas tata kelola BUMDes dengan Pemerintah Desa dan masyarakat secara partisipatif untuk mengatasi masalah ketidakberdayaan.

4. Minimnya kegiatan pengorganisasian BUMDes Lubuk Kertang dalam mengimplementasikan ide-ide kreatif dan produktif dalam pengembangan unit usaha yang mampu meningkatkan perekonomian desa.

Oleh karena itu, tujaun dari kegiatan ini adalah:
1. Peningkatan kemampuan pengurus BUMDes Lubuk Kertang dalam memetakan potensi desa berdasarkan potensi sumberdaya yang ada.

2. Peningkatan kemampuan pengurus BUMDes Lubuk Kertang dalam memahami tata kelola BUMDes yang baik dan benar, sehingga mampu bersinergi dengan Pemerintah Desa Lubuk Kertang dan masyarakat sebagai pelaku wirausaha desa

3. Peningkatan kemampuan pengurus BUMDes Lubuk Kertang dalam mengembangkan unit usaha yang produktif untuk meningkatkan perekonomian desa.

4. Peningkatan kemampuan pengorganisasian pengurus BUMDes Lubuk Kertang dalam melakukan pengorganisasian dalam mengimplementasikan ide-ide kreatif dan produktif dalam pengembangan unit usaha yang mampu meningkatkan perekonomian desa.

\section{METODE PELAKSANAAN KEGIATAN}

Metode yang dilakukan dalam kegiatan ini adalah:

1. Sosialisasi kegiatan pelatihan penguatan ekonomi BUMDes Lubuk Kertang Melalui Pemetaan potensi desa secara partisipatif. Sosialisasi dilakukan dengan melakukan presentasi terhadap pengurus BUMDes Lubuk Kertang secara interaktif dan partisipatif terkait peningkatan kapasitas (capacity building) dalam peningkatan kualitas BUMDes [4]. 
2. Pelatihan Penguatan Ekonomi BUMDes Lubuk Kertang Melalui Pemetaan Potensi Desa Secara Patisipatif. Pelatihan ini diberikan kepada pengurus BUMDes yang ada di Desa Lubuk Kertang.Pelatihan dilakukan dengan melakukan presentasi terhadap aparatur desa secara interaktif dan partisipatif terkait peningkatan kapasitas (capacity building) yang dilakukan oleh Tim yang didampingi oleh Tim pengabdi yang bertugas sebagai narasumber. Dalam pelatihan ini, Tim Pengabdi juga memberikan bantuan teknologi tepat guna kepada pengurus BUMDes yang telah terbentuk, berupa: pelatihan penguatan ekonomi BUMDes Lubuk Kertang, baik dalam hal pemetaan potensi desa, pemilihan unit usaha usaha, tata kelola, pengembangan unit usaha dan pengorganisasian,

3. Penguatan Tata Kelola Melalui Pengembangan Unit Usaha BUMDes Lubuk Kertang.

Kegiatan ini dilakukan dengan memberikan bantuan kertas kerja, pemetaan potensi desa modul tata kelola BUMDes kepada aparatur desa untuk memudahkan peserta dalam memahamai tata kelola dan pengembangan unit usaha yang efektif, efisien, transparan dan akuntabel. Pendekatan ini mengenal dua langkah utama, yaitu: penyadaran (conscientization) di tingkat individu dan pengorganisasian (community organization) di tingkat struktur dan sistem [4].
4. Melakukan monitoringdan evaluasi terhadap aparatur BUMDes Lubuk Kertang di Desa Lubuk Kertang Kecamatan Brandan Barat dalam melaksanakan penguatan ekonomi BUMDes. Monitorng dan evaluasi ini dilakukan sebulan setelah pelatihan tersebut.

5. Publikasi. Laporan kegiatan yang telah disusun selanjutnya disusun menjadi materi publikasi yang akan dituangkan dalam bentuk publikasi yang disepakati bersama mitra desa.Publikasi berupa artikel ilmiah pada jurnal ber ISSN atau prosiding ilmiah ber ISBN dan video kegiatan yang dipublikasi melalui youtube.

\section{HASIL DAN PEMBAHASAN}

Kegiatan ini dilakukan 1 bulan sebelum kegiatan pelatihan penguatan ekonomi BUMDes Lubuk Kertang Melalui Pemetaan potensi desa secara partisipatif dilaksanakan. Dalam sosialisasi ini tim pelaksana datang berkunjung ke kantor BUMDes Lubuk Kertang Kecamatan Brandan Barat Kabupaten Langkat dan bertemu dengan Direktur BUMDes (Maqwal Firdaus) untuk membicarakan tentang kegiatan pelatihan yang akan dilaksanakan. Sosialisasi dilaksanakan secara informal dengan metode diskusi kelompok dengan pengurus BUMDes. Terjalin diskusi dua arah yang efektif dalam bina suasana yang kondusif dan interaktif.

Pelatihan diberikan kepada pengurus BUMDES yang ada di Desa Lubuk Kertang. 
Antusiasme pengurus BUMDes Lubuk manusia, sumberdaya fisik, sumberdaya Kertang mendapatkan apresiasi dari pihak kecamatan, sehingga pihak kecamatan meminta pengurus BUMDes dari 5 desa yang ada di kecamatan Brandan Barat untuk ikut bergabung dalam pelatihan ini. Pelatihan ini terlebih dahulu dibuka oleh Camat Brandan Barat, sekaligus memberikan pemaparan tentang urgensitas pelatihan ini dilaksanakan bagi pengembangan BUMDes. Camat berharap luaran dari kegiatan ini dapat meningkatkan kemampuan BUMDes seKecamatan Brandan Barat, khususnya Desa Lubuk Kertang dalam menemukenali potensi desa untuk kemudian menjadi peluang usaha yang dikembangkan.

Selanjutnya pelatihan dimulai oleh Ketua Tim Pelaksana menegaskan bahwa kegiatan ini bertujuan untuk penguatan ekonomi BUMDes Lubuk Kertang melalui pemetaan potensi desa secara partisipatif, sehingga mampu mendorong BUMDes menjadi badan usaha yang mampu mengenali potensi sumberdaya yang ada serta mampu bersaing dengan BUMDes lainnya yang tersebar di wilayah Indonesia pada umumnya dan di Provinsi Sumatera Utara pada khususnya. Dalam sesi pemaparan yang disampaikan Ketua Tim Pengusul (Dr. Yeni Absah, SE, M.Si) menegaskan bahwa Badan Usaha Millik Desa (BUMDes) agar jangan salah memilih jenis usaha yang dikembangkan. Pengurus BUMDes harus mampu menemukenali potensi sumberdaya yang ada di desa. Potensi sumberdaya tersebut mencakup: sumberdaya alam, sumberdaya sosial dan sumberdaya finansial (keuangan). Kesemua sumberdaya tersebut harus dianalisis dari kerentanan dan kebijakan yang terjadi di wilayah masing-masing desa. Kemampuan mengidentifikasi potensi sumberdaya ini akan menjadi dasar dalam proses pengambilan keputusan bersama yang dibahas dalam musyawarah desa (musdes) yang akan menjadi ahir dalam penentuan sentra dan unit usaha yang akan dikembangkan. Dalam kesempatan itu juga dipaparkan pengambilan keputusan untuk mengembangkan unit usaha harus melibatkan 3 elemen penting di desa yaitu: pengurus BUMDes, Kepala Desa dan Badan Permusyawaratan Desa (BPD), sehingga tercipta sinergitas yang baik dalam proses pengambilam keputusan melalui musyawarah desa.

Pada sesi berikutnya, pelaksanaan praktik pemetaan potensi desa secara partisipatif dengan mengajak seluruh pengelola BUMDes, aparat desa dan BPD dari 5 desa untuk mempraktikkannya secara visual melalui beberapa kertas kerja yang diberikan Tim pelaksana Pengabdian Kepada Masyarakat untuk dikerjakan secara partisipatif. Kertas kerja telah difasilitasi oleh Tim Pelaksana Pengabdian kepada Masyarakat beserta media tulis lainnya (pulpen, spidol marker, spidol warna-warni). Ada pun kelima kertas kerja tersebut terdiri dari:

- Kertas kerja plano untuk menggambarkan sketsa desa sekaligus 
mengidentifikasi batas-batas desa, menjadi sebuah konsep bisnis yang akan kondisi permukiman dan potensi sumberdaya apa saja yang ada di desa masing-masing yang disimbolkan melalui gambar dan warna tertentu.

- Setelah masing-masing potensi sumberdaya yang ada di desa telah berhasil diidentifikasi melalui simbolisasi visual dalam ertas kerja sebelumnya, maka peserta melanjutkan dengan mengisi matriks (tabel) yang terdiri dari beberapa kolom dari 5 potensi modal yang ada (fisik, alam sosial, manusia, finansial). Dalam hal ini diperlukan diskusi kelompok dari masing-masing desa dalam mengisi kolom yang tertera di masing-masing tabel, mencakup: (kondisi sumberdaya, morfologinya, kondisi fisik dan rencana ke depan)

- Kertas kerja pemetaan potensi dan pemilihan usaha. Setelah sketsa desa tergambar beserta potensi desa teridentifikasi, maka dilanjutkan dengan menuangkan potensi usaha yang sudah teridentifikasi berdasarkan besaran potensi yang telah diprakirakan oleh peserta.

- Setelah itu, peserta akan melakukan analisa kondisi eksternal dan internal dari masing-masing potensi sumberdaya yang sudah terpetakan tersebut. Selanjutnya, akan dijelaskan nilai tambah, berupa: keunikan dan keunggulan masing-masing sebelum menjadikan potensi usaha tersebut 
antara Tim Pelaksana, apartur Desa Lubuk Kertang dan pengurus BUMDes Lubuk Kertang. Group Whatssapp ini dibentuk sebagai wadah pertukaran informasi terhadap kendala-kendala yang ditemukan dalam proses penggunaan sistem ini. Selain itu, group whatssapp dapat menjadi saluran informasi untuk memantau perkembangan BUMDes Lubuk Kertang, khususnya dalam pemetaan potensi desa dan pemelihan jenis usaha yang akan dikembangkan.

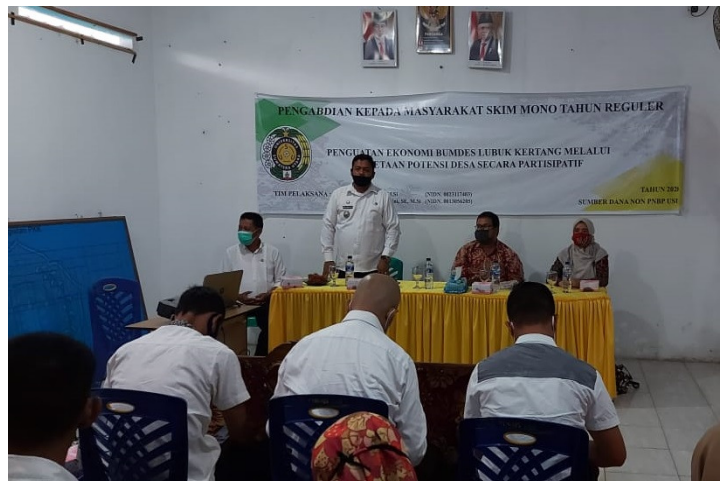

Gambar 1. Susana Pengabdian Kepada Masyarakat Pelatihan Penguatan Ekonomi BUMDes Melalui Potensi Desa Secara Partsipatif

\section{KESIMPULAN}

Kesimpulan yang dapat diambil dari kegiatan pengabdian masyarakat dengan skim mono tahun reguler ini adalah:

1. Antusias pengurus BUMDes Lubuk Kertang dan 4 Bumdes lainnya seKecamatan Brandan Barat dalam pelatihan ini sangat besar. Hal ini ditunjukkan dalam bentuk kemudahan dalam pelaksanaan kegiatan pengabdian dan partisipasi kehadiran yang konsisten dalam setiap kegiatan (FGD dan pelatihan).

2. Kegiatan ini memiliki potensi yang besar untuk ditindaklanjuti dalam bentuk membentuk unit usaha BUMDes berdasarkan hasil pemetaan potensi desa dan peluang usaha yang partisipatif.

3. Keputusan untuk menentukan konsep bisnis/ usaha yang merupakan tindak lanjut dari pemetaan potensi dan peluang usaha merupakan hasil kesepakatan bersama yang diambil melalui musyawarah desa (musdes) yang melibatkan pengurus BUMDes, Perangkat Desa dan Badan Permusyawaratan Desa (BPD)

4. Pelatihan penguatan ekonomi BUMDes melalui pemetaan potensi desa secara partisipatif ini dapat mendorong BUMDes Lubuk Kertang menjadi BUMDes yang unggul dalam menentukan konsep bisnis/ usaha yang dijalankan, sehingga mampu bersaing dengan BUMDes lainnya.

\section{SARAN}

Saran yang diberikan dalam kegiatan ini adalah sebagai berikut :

\section{Kepada Kelompok Mitra (BUMDes} Lubuk Kertang), untuk terus menerus memantau dan mengimplementasi unit usaha yang dikembangkan melalui seluruh stakeholder yang terkait untuk pemantaban konsep bisnis/ usaha berdasarkan analisis potensi desa.

2. Melakukan pembinaan dari Perguruan Tinggi terkait baik dari segi tata kelola BUMDes maupun analisis pemetaan potensi desa.

3. Pemerintah Kabupaten Langkat menjadikan program penguatan ekonomi BUMDes melalui pemetaan potensi desa 
secara partisipatif ini sebagai salah satu program pembangunan desa. Mengingat potensi BUMDes sangat besar dalam mengembangkan pendapatan asli desa melalui pengembangan BUMDes ke depannya.

\section{UCAPAN TERIMA KASIH}

Ucapan terima kasih kepada Lembaga

Pengabdian Pada Masyarakat (LPPM)

Universitas Sumatera Utara melalui

ProgramMono Tahun Reguler yang

bersumber dari Dana Non PNBP 2020

\section{REFERENSI}

[1] Abidin, H Z. (2017). Pemetaan Desa untuk Percepatan Pembangunan Desa dan Kawasan Perdesaan. Badan Informasi Geospasial, Bogor. Diakses dari http://www.keuangandesa.com/ wpcontent/uploads/2017/06/Pemetaan-
Desa-untuk-Percepatan-PembangunanDesa-dan Kawasan Perdesaan.pdf . Diakses 25 Juli 2018

[2] Budiman, Arif. $1995 . \quad$ Teori Pembangunan Dunia Ketiga, Jakarta: Gramedia Pustaka Utama. Hal: 10-13

[3] Hamzah, Ardi, 2015. Tata Kelola Pemerintah Desa Menuju Desa Mandiri, Sejahtera dan Partisipatoris, Penerbit Pustaka, Banyuwangi. Hal; 21-23

[4] Moeljiarto. Santoso. 2003. "Bidang Pendidikan dan Kesehatan dalam Pembangunan Sosial" Dalam Analisis CSIS Pemberdayaan Masyarakat Lapis Bawah", CSIS. Tahun XXVI, No. 1 Januari-Februari 1997, Jakarta.

[5] M. Zulkarnain, Reza, 2016. Pengembangan Potensi Ekonomi Desa Melalui BUMDesa Pondok Salam Kabupaten Purwakarta. Universitas Padjajaran, Purawakarta. Hal:35

[6] Suparjan. Moehammad. 2003. Pengembangan Masyarakat Dari Pembangunan Sampai Pemberdayaan, Aditya Media, Yogyakarta. Hal:51-53 